\title{
Equipment-related incidents in the operating room: an analysis of occurrence, underlying causes and consequences for the clinical process
}

\author{
I Wubben, ${ }^{1}$ J G van Manen, ${ }^{1}$ B J van den Akker, $^{2}$ S R Vaartjes, ${ }^{3}$ W H van Harten ${ }^{1}$
}

${ }^{1}$ University of Twente, School of Management and Governance, Department of Health

Technology and Services Research, Enschede, The Netherlands

${ }^{2}$ Isala Klinieken, Hospital, Operation Rooms Department, Zwolle, The Netherlands ${ }^{3}$ Medisch Spectrum Twente Department of Medical Physics, Hospital, Enschede, The Netherlands

\section{Correspondence to} Dr W H van Harten, University of Twente, Department of Health Technology and Services Research, P0 Box 217, $7500 \mathrm{AE}$ Enschede, The Netherlands; w.h.vanharten@utwente.nl

Accepted 4 March 2010 Published Online First 16 June 2010

\section{ABSTRACT}

Background Equipment-related incidents in the operating room (OR) can affect quality of care. In this study, the authors determined the occurrence and effects on the care process in a large teaching hospital. Methods During a 4-week period, OR nurses reported equipment-related incidents during surgery procedures in both locations of the hospital. The incidents were reported using a separate form for each incident. A structured analysis (PRISMA) was used to analyse incidents that resulted in serious delays (>15 min). Results Forms were returned for 911 out of 1580 surgeries (57.7\%). In total, 148 incidents were registered, relating to a total of $29 \mathrm{~h}$ and $45 \mathrm{~min}$ of extra work. In addition, $12 \mathrm{~h}$ and 9 min of operational delay was registered. Most incidents involved instruments (46\%) or medical devices (28\%). 68\% occurred during surgery and $32 \%$ during the preparation phase. No direct physical harm was reported, although indirect harm, like longer anaesthesia, did occur and can be defined as an adverse event. $10 \%$ of the incidents led to a delay of over $15 \mathrm{~min}$. For these incidents, 'management decisions' (eg, inventory capacity, planning procedure) was the most encountered root cause. Only six out of the 148 incidents found corresponded with the blamefree reporting database.

Conclusions Equipment-related incidents occurred frequently in the involved hospital sites (up to 15.9\%) and resulted in some extra work and additional minutes of delay per event. Management decisions have considerable influence on the occurrence of equipmentrelated incidents. There was serious under-reporting of incidents.

Literature suggests that adverse events in hospitals occur at unacceptably high rates $^{1-5}$ and that a considerable percentage are preventable. ${ }^{2} 36$ The exact number of (near) incidents in hospitals is unknown, as good incident-reporting systems are lacking or are used inconsistently. ${ }^{7}$ With respect to incidents in the operating room (OR), Cooper concludes in two studies that $14 \%$ of incidents during anaesthesia procedures are the result of overt equipment failure. ${ }^{89}$ In addition, 'equipment design was indictable in many categories of human error, as were inadequate experience and insufficient familiarity with equipment. ${ }^{8}$ This distinction in error causation can be related to active and latent failures. ${ }^{10}$ Active failures are the unsafe acts committed by people who are in direct contact with the patient or system, and latent conditions are the weaknesses in defence mechanisms created by designers, builders or management.
Also government agencies stress the importance of adequate equipment management. ${ }^{11} 12$ In addition, equipment is an important factor to be considered in OR scheduling. ${ }^{14}$ Equipment-related incidents are listed among the most common causes of delay in the $\mathrm{OR}$, after the late arrival of surgeons or anaesthetists. ${ }^{15} 16$ Furthermore, many interruptions that were found in previous studies are related to equipment. ${ }^{17} 18$ As interruptions during surgery might lead to adverse events, ${ }^{19} 20$ streamlining all processes involving equipment will reduce risks by reducing the number of interruptions. We could not find any literature reporting on prospective inventories of equipment-related incidents, irrespective of nature or background, and its effect on continuity and safety of the operating room processes. This study sought to determine (1) the occurrence of equipment-related incidents in the OR, (2) the effect of these incidents on the continuity of the clinical process and (3) the underlying causes of these incidents.

\section{METHODS \\ Research setting}

This study was performed in a large, non-academic teaching hospital in The Netherlands that performs approximately 30000 surgical procedures a year. The hospital has two locations, and surgery is performed in both. The study focused on clinical ORs, and procedures performed in day care were not taken into account. Eighteen clinical ORs are available across both locations $(8+10)$, and most ORs are dedicated to specific specialities. There is just one OR dedicated to emergency procedures, which was included in this study. The OR nurses work at both locations in a circulating system.

\section{Data collection}

All OR nurses were asked to fill in one registration form (see appendix 1) after each surgery procedure during a 4-week registration period in January-February 2009 (1580 procedures). Using this form, they registered the date, patient number and whether or not an equipment-related incident occurred. An equipment-related incident is defined as all activities with equipment that did not go according to plan. The combination of date and patient number made it possible to retrieve additional data (specialty, type of surgery procedure, OR number) from a database. When an incident was registered, additional questions were answered on the reverse side of the form. Here, information about the incident (time, type of incident, type of equipment involved; see table 1), consequences 
Table 1 Definitions of equipment categories and incident categories with illustrative examples

\begin{tabular}{|c|c|}
\hline Category and definition & Illustrative example(s) \\
\hline $\begin{array}{l}\text { Medical device: } \\
\text { Equipment that is used during the surgery procedure. Needs to be powered and } \\
\text { gives information and/or has moving parts. Repairs and inspections are done by the } \\
\text { department of Medical Technology. }\end{array}$ & Video carts, infusion pumps, x-rays \\
\hline $\begin{array}{l}\text { Instruments: } \\
\text { Equipment that is durable and does not need power. Most instruments are treated } \\
\text { by the sterilisation department. }\end{array}$ & $\begin{array}{l}\text { Everything in a set of instruments-for example, scalpels, scissors and tweezers. } \\
\text { Furthermore, add-ons for medical devices for example, saws, drills and scopes are } \\
\text { defined as instruments. }\end{array}$ \\
\hline $\begin{array}{l}\text { (Disposable) Materials: } \\
\text { (Bulk) products that are disposable after use. Furthermore, durable products that do } \\
\text { not need to be sterile or powered are defined as materials. }\end{array}$ & $\begin{array}{l}\text { Bulk products such as needles, plasters and bandages. Furthermore, the materials } \\
\text { category contains products such as implants and ECG cables. }\end{array}$ \\
\hline $\begin{array}{l}\text { Facilitating equipment: } \\
\text { Equipment that has a supporting function in the } \mathrm{OR}\end{array}$ & $\begin{array}{l}\text { Equipment such as specialised operating room-doors, air-filtering systems, operating } \\
\text { room-tables, operating room-lighting, non-medical computers and telephones }\end{array}$ \\
\hline $\begin{array}{l}\text { Equipment not available: } \\
\text { Equipment that cannot be found, that is in use already, or is not sterile }\end{array}$ & $\begin{array}{l}\text { Special implants were sent to the hospital but arrived at the wrong location. Surgery } \\
\text { was postponed until transportation to the other location was arranged. }\end{array}$ \\
\hline $\begin{array}{l}\text { Failing equipment: } \\
\text { Equipment that fails while using or testing it }\end{array}$ & $\begin{array}{l}\text { During a minimal invasive surgery procedure, images on the video cart were no } \\
\text { longer visible. A broken scope needed replacement in order to regain visual contact. }\end{array}$ \\
\hline $\begin{array}{l}\text { Misuse: } \\
\text { Using equipment in an improper way by operating room employees }\end{array}$ & $\begin{array}{l}\text { While lowering the operating room table, a bedspread was crushed between the } \\
\text { sliding mechanism. This stopped the operating room table from moving, and } \\
\text { a replacement was used. }\end{array}$ \\
\hline Other: & \\
\hline All incidents that cannot be placed in the categories unavailable, failing or misuse. & $\begin{array}{l}\text { A bearhugger blanket for warming the patient was available, but could not be used } \\
\text { due to protocol issues }\end{array}$ \\
\hline
\end{tabular}

(extra work, delay, patient related) and probable causes were recorded.

The registration form was draughted and tested in a pilot study in cooperation with OR nurses to verify the practical and theoretical content; the methodological characteristics of the forms were not otherwise tested.

The registration forms were printed in a prominent colour and were present in each OR. After the forms were completed, they were returned to the secretary of the OR complex where they were picked up daily for processing. For the forms that were incomplete or unclear, emails or interviews (by phone or face to face) were used to retrieve the missing data or to clarify the registered incident.

In addition, the OR nurses were instructed to continue to register incidents in the blame-free reporting database in order to be able to compare the number and type of incidents in this database with the results of our study, as the management felt that there might be under-reporting in this database.

\section{Data analysis}

$\chi^{2}$ tests were used to determine whether there were any statistically significant differences in incidents between the two locations, specialities, etc $(\mathrm{p}<0.05)$.

Furthermore, a PRISMA analysis ${ }^{21} 22$ was used to analyse the causes of incidents that resulted in a delay of $15 \mathrm{~min}$ or more. These incidents were considered to be 'serious' by the hospital management. The PRISMA analysis consists of three steps: creating causal trees for the occurred incidents (using interviews with the OR nurses), categorising the root causes using the ECM model $^{21}$ and suggesting interventions to reduce the occurrence or consequences of incidents.

The PRISMA method was supervised by the main author. The researcher did not follow any formal training but extensively studied all related literature and an instruction DVD. File access and staff interviews were used to retrieve the required data, and conclusions were verified by the involved staff and one of the coauthors (BJvdA) with extensive experience in equipmentrelated issues in the OR environment.
Finally, the data were compared with the data in the blamefree reporting database to verify the completeness of the data in both this study and the database itself.

\section{RESULTS}

\section{Occurrence of equipment-related incidents}

The final sample (representing a $57.7 \%$ response rate) included 933 registration forms representing 911 procedures (multiple incidents occurred during 15 procedures); 167 incidents are registered on these forms. Nineteen of these incidents, however, were excluded, as they were not equipment-related (5) or were reported repeatedly, as the problem (an air-conditioning system blowing very cold air) was not solved within a week (14; inclusion would distort the results). The resulting 148 incidents are included in this study, representing a registered incident percentage of $15.9 \%$ (table 2 ).

The $\chi^{2}$ test did not show any significant differences in the occurrence of incidents between location $\mathrm{A}$ and $\mathrm{B}$. The distribution of the incidents over the two locations, related to timing, equipment categories and incident types, is shown in table 3 . The most common types of equipment involved in incidents were surgical instruments (46\%), followed by medical devices (28\%), facilitating equipment (16\%) and materials $(10 \%$; see table 1 for definitions). Concerning the type of incident, $93 \%$ of the incidents could be categorised as 'equipment unavailable' (45\%; often instruments) or 'failing equipment' (49\%; often

Table 2 Overall occurrence of registered equipment-related incidents (by hospital location)

\begin{tabular}{llll}
\hline Hospital location & A & B & Total \\
\hline $\begin{array}{l}\text { Performed surgery procedures } \\
\text { during study }\end{array}$ & 861 & 719 & 1580 \\
$\begin{array}{l}\text { Returned registration forms } \\
\text { (percentage of total)459 (53.3\%) }\end{array}$ & $474(65.9 \%)$ & $933(59.1 \%)$ & \\
Registered incidents & 86 & 81 & 167 \\
$\begin{array}{l}\text { Incidents excluded } \\
\text { Incidents included (percentage of }\end{array}$ & $68(14.8 \%)$ & $80(16.9 \%)$ & $148(15.9 \%)$ \\
total no of forms) & & & 19 \\
\hline
\end{tabular}


Table 3 Occurrence of registered equipment-related incidents (by location)

\begin{tabular}{lllr}
\hline & $\begin{array}{l}\text { Location A } \\
\text { no of incidents }\end{array}$ & $\begin{array}{l}\text { Location B } \\
\text { no of incidents }\end{array}$ & $\begin{array}{l}\text { Total no of } \\
\text { incidents (\%) }\end{array}$ \\
\hline $\begin{array}{l}\text { Timing of incidents } \\
\quad \text { During preparation }\end{array}$ & 22 & & $47(31.8)$ \\
$\quad \begin{array}{l}\text { During surgery } \\
\text { Equipment category }\end{array}$ & 46 & 55 & $101(68.2)$ \\
$\quad$ Medical devices & 21 & & \\
Instruments & 27 & 21 & $42(28.4)$ \\
Materials & 12 & 41 & $68(45.9)$ \\
$\quad$ Facilitating & 8 & 3 & $15(10.1)$ \\
Type of problem & 15 & $23(15.5)$ \\
$\quad$ Equipment not available & 30 & 36 & $66(44.6)$ \\
Broken equipment & 34 & 38 & $72(48.6)$ \\
Misuse & 2 & 3 & $5(3.4)$ \\
Other (ie, procedural & 2 & 3 & $5(3.4)$ \\
problems) & & & \\
\hline N=148. & & &
\end{tabular}

medical devices). Finally, incident percentages were above average for specialities using the most (advanced) equipment, such as neurology (26.4\%), orthopaedics (20.8\%), urology $(20.5 \%)$ and thorax surgery $(17.9 \%)$ (not in table).

\section{Consequences of equipment-related incidents}

The 148 incidents mentioned above caused a total of $29 \mathrm{~h}$ and $45 \mathrm{~min}$ of extra work for the OR nurses. Waiting time is not included in this number, defined as the time that OR nurses in the $\mathrm{OR}$ are actually waiting, without preparing a later phase of the procedure. On average, this results in extra work for the OR nurses of $12.1 \mathrm{~min}$ per recorded incident $(S D=16.9)$. Seventy of these incidents $(47.3 \%$ ) eventually led to a delay (defined as the time that the entire procedure was halted) for the clinical process in the OR. The total amount of delay registered in this study in the OR was $12 \mathrm{~h}$ and 9 min (on average 5 min per incident, $\mathrm{SD}=9.9$ ). The 15 'serious' incidents (analysed using the PRISMA methodology) represented only $10 \%$ of the total number of incidents but resulted in $61 \%$ of the total registered delay (explaining the high SD for the average delay).

According to the OR nurses, none of the incidents directly resulted in physical harm. However, patients were affected indirectly by longer anaesthesia as a result of 29 incidents $(19.6 \%)$ and postponed procedures as a result of two incidents $(1.4 \%)$, so these incidents can be defined as adverse events. ${ }^{23} 24$ In the same period, only 10 equipment-related incidents were reported in the blame-free incident reporting system, of which only one related to a serious delay case. Six out of these 10 were also registered for the present study using the registration forms.

\section{Causes for equipment-related incidents}

The cause of an incident was often unknown to the responding OR nurse (27.7\%). Failing equipment $(21.6 \%)$ and incomplete instrument sets $(14.2 \%)$ were the top categories for the incidents where the cause was determined. Other causes determined by OR nurses are misuse (6.1\%), non-sterile equipment $(5.4 \%)$, communication errors (4.1\%), planning errors $(1.4 \%)$ and causes that were listed only once $(18.9 \%)$.

Causal trees were derived for 15 incidents that caused 'serious' delay (>15 min). Classifying all root causes resulted in the

Table 4 PRISMA profile of the 15 'serious' incidents ${ }^{21}$ 22*

\begin{tabular}{|c|c|c|}
\hline Root-causes identified in PRISMA analysis ${ }^{21} 22$ & No & Examples from related study \\
\hline \multicolumn{3}{|l|}{ Technical } \\
\hline T-ex (External) & - & \\
\hline TD (Design) & 2 & Malfunctioning software in navigation equipment \\
\hline TC (Construction) & - & \\
\hline TM (Materials) & 5 & Scope made of fibreglass is internally broken \\
\hline \multicolumn{3}{|l|}{ Organisational } \\
\hline 0-ex (External) & 1 & $\begin{array}{l}\text { No intensive care bed available for patient that needs other type of surgery (intensive care and operating } \\
\text { room are separately managed department) }\end{array}$ \\
\hline OK (Transfer of Knowledge) & - & \\
\hline OP (Protocols) & 2 & $\begin{array}{l}\text { Multiple types of video carts are available. Surgeons prefer a certain type and use this one when } \\
\text { available, even if they can perform the surgery with an older type. Now, another surgery that needed this } \\
\text { specific video cart was delayed by the unavailability (lack of procedures). }\end{array}$ \\
\hline OM (Management priorities) & 13 & $\begin{array}{l}\text { Decision to do five identical procedures in } 1 \text { day, while only three sets are available. Delay in sterilisation } \\
\text { process causes delays in the operating room. }\end{array}$ \\
\hline OC (Culture) & - & \\
\hline \multicolumn{3}{|l|}{ Human } \\
\hline H-ex (external) & 4 & Surgical instruments are missing in instrument set (human error in sterilisation department) \\
\hline HKK (Knowledge) & - & \\
\hline HRO (Qualifications) & - & \\
\hline HRC (Coordination) & 2 & $\begin{array}{l}\text { Surgeon decides to perform other type of surgery when patient is already in the operating room } \\
\text { (equipment was not available yet) }\end{array}$ \\
\hline HRV (Verification) & - & \\
\hline HRI (Intervention) & 7 & Wrong use of instrument resulted in broken screws \\
\hline HRM (Monitoring) & 2 & $\begin{array}{l}\text { Operating room nurse responsible for refilling the stock, forgot to check the number of materials in } \\
\text { a certain operating room, resulting in a shortage }\end{array}$ \\
\hline HSS (Slips) & - & \\
\hline HST (Tripping) & - & \\
\hline \multicolumn{3}{|l|}{ Other } \\
\hline PRF (patient-related factor) & 2 & $\begin{array}{l}\text { First surgery procedure was performed in another country where other types of orthopaedic materials } \\
\text { were used. Other instruments were needed when this was noticed. }\end{array}$ \\
\hline X (Unclassifiable) & - & \\
\hline
\end{tabular}


profile shown in table 4. An example of such an analysis is provided in figure 1. 'Management Priorities' is the category that is determined most often (13), followed by 'Human intervention'(7) and 'Materials' (4). This 'Management Priorities' category as described by van Vuuren 'Refers to failures resulting from management decisions in which safety is relegated to an inferior position when faced with conflicting demands or objectives. ${ }^{21}$ In this study, we found incidents due to inventory capacity planning (8), scheduling issues (3) and the configuration of instrument sets (2). In all these cases, costs and productivity were factors that were prioritised by management above the risk of incidents.

\section{CONCLUSION AND DISCUSSION}

In this study, we have found that equipment-related incidents in the OR are a common phenomenon, occurring in up to $15.9 \%$ of surgery procedures. These incidents result on average in $12 \mathrm{~min}$ of extra work and 5 min delay per incident, affecting the continuity of the clinical process. Furthermore, we have found that decisions made by management have a considerable influence on the delay caused by equipment-related incidents. Finally, we found a large discrepancy between the number of incidents registered in this study and the blame-free reporting database, indicating serious under-reporting.

The incident percentage found in this study (15.9\%) might not represent the actual occurrence due to the uncertainty caused by the response rate $(57.7 \%)$. For both locations, there was a significant positive correlation $(0.64$ and $0.54, \mathrm{p}<0.05)$ between this response rate and the number of registered incidents during a day. OR nurses were probably more motivated to fill in a form for procedures when confronted with an incident. Therefore, the actual occurrence is likely to be somewhat lower than the percentage of $15.9 \%$ that is found in this study but will be at least $9.4 \%$.

As only the extra work for OR nurses was registered, the consequences in terms of extra work are probably underestimated. Additional work can be incurred for various departments such as planning, the medical technology department and nursing wards.
Although there was no dip in reported incidents in the blamefree reporting database during this research, it showed that only 10 equipment-related incidents were reported during this study, confirming that current incident reporting systems are used inconsistently. ${ }^{7}$ It is understandable that $O R$ nurses were reluctant to register all incidents by blame-free reporting, as it consumes a considerable amount of time, and many incidents were only minor interruptions that did not harm the patient. However, a serious under-reporting was found for the 'serious' incidents as well (one out of 15 was registered). This suggests a considerable potential for improvement; if proper incident reporting and follow-up are realised this can result in a lower occurrence of incidents. ${ }^{25}$

For the 15 incidents causing a delay of 15 min or longer, multiple root causes were derived by conducting interviews (PRISMA analysis). Although 15 incidents is a relatively low number for an aggregated PRISMA analysis, the profile of classified root causes clearly distinguished the most important factors (table 4).

As a result of the PRISMA analysis, the hospital under review is advised to re-evaluate its inventory capacity of equipment (especially instruments). Furthermore, they are advised to re-evaluate the procedures for the sterilisation department, as many incidents were the result of incomplete (21) or non-sterile (seven) instrument sets. Lastly, we recommend that the hospital should consider renewing its procedures for reporting defective equipment, as two incidents were caused by defective equipment that had already caused problems but was not reported to other OR nurses. Methods to reduce incidents, such as a checklist including a time-out procedure ${ }^{26}$ and proper equipment maintenance, ${ }^{5}$ were already in place but did not seem to be watertight.

This study has some limitations. Assessing the representativeness of our findings for other hospitals requires further research. Furthermore, the response rate of $57.7 \%$ creates some uncertainty in the data resulting from the chosen method of registration by $\mathrm{OR}$ nurses. Direct observation by trained and independent researchers would have constituted an ideal method to validate the OR nurses' reports at the end of each case. However, this was not feasible due to time and cost

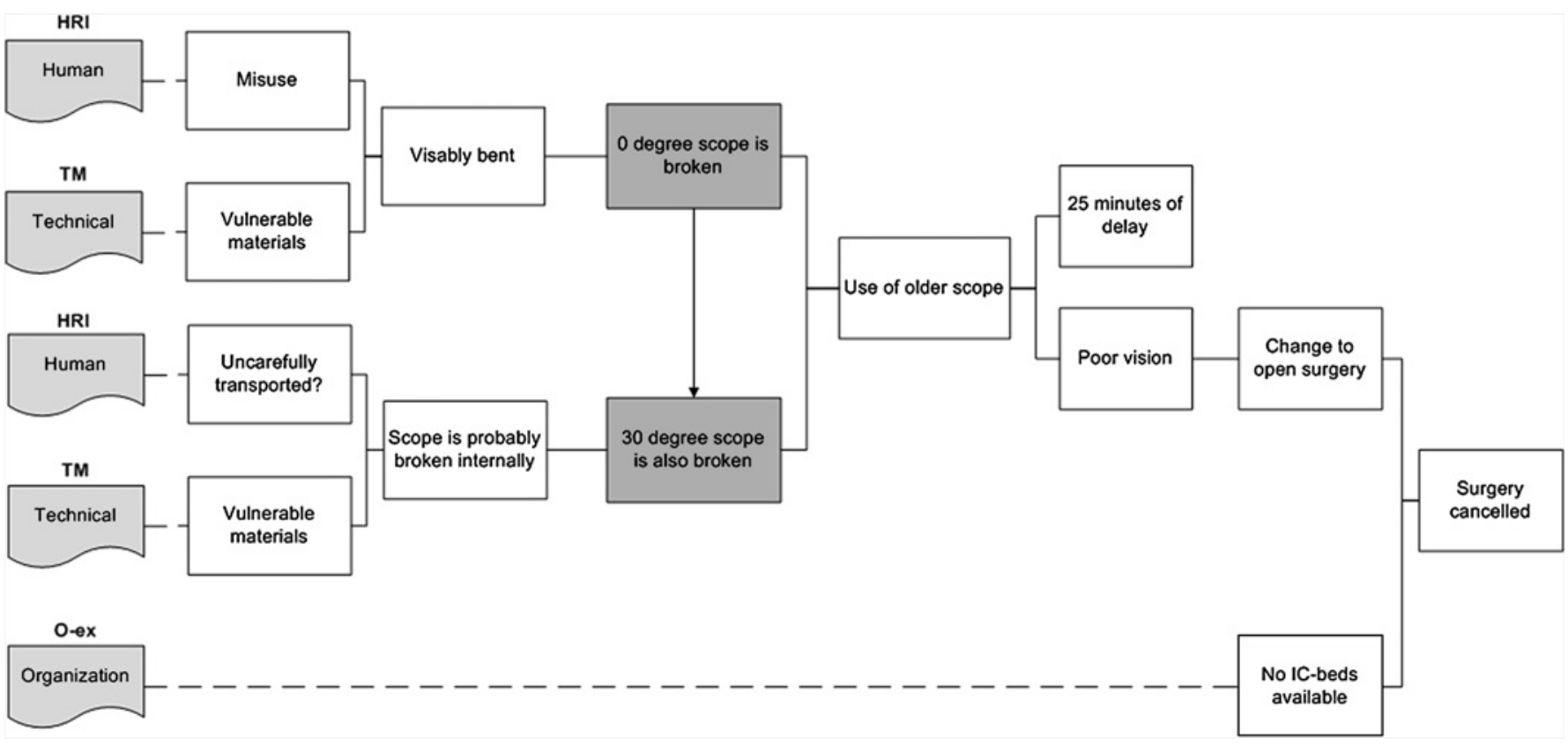

Figure 1 Broken scopes leading to considerable delay and a cancelled procedure. 
restraints. It can be presumed that more, possibly less significant, incidents would have been reported, leading to higher figures than those presented here. Also, a higher percentage of 'misuse' would probably be reported, as is the case in other studies. ${ }^{5,8}$ It is also possible that the choice of registration by $\mathrm{OR}$ nurses, instead of surgeons or anaesthetists, creates a professional bias. The validity of the measurements was not formally tested; it is likely, though, that the instrument used is valid for this research purpose, as we encountered no questions from the OR nurses, and missing items in the questionnaire were very rare. Lastly, the PRISMA analysis of the most serious incidents provides a relevant overview of causes; in view of the scoring options, considerably larger numbers are, however, needed to present a stable profile of root causes.

Notwithstanding these limitations, the findings of this study provide insight into the occurrence and effect of equipmentrelated incidents. The effects of these incidents on extra work and discontinuity of clinical processes in the OR are not negligible, underlining the statement that this factor should be included in risk assessments for equipment. ${ }^{13}$

Future research should indicate if the results of this study can be confirmed in other hospitals as well. Research concerning the extra resources that are needed due to equipment-related incidents might also be very interesting - not only for the OR department, but for the entire organisation, as delays and waiting time seem to have a knock-on effect on other departments. Furthermore, research is needed into the most efficient and appropriate way to estimate the local risks concerning equipment failure, as incident reporting does not seem to suffice. From a methodological viewpoint, it is not yet clear whether a prospective risk analysis will completely cover the wide array of problems that can be encountered. Apart from human and organisational factors, equipment-related factors are one of the main causes of adverse events; equipment-related incidents occur with such frequency that further attention to its causes and effects seems justified.

Competing interests None.

Provenance and peer review Not commissioned; externally peer reviewed.

\section{REFERENCES}

1. Kohn LT, Corrigan JM, Donaldson MS, et al. To err is human: building a safer health system. Washington, DC: National Academy Press, 2000.

2. Zegers M, De Bruijne MC, Wagner $\mathrm{C}$, et al. Adverse events and potentially preventable deaths in Dutch hospitals: results of a retrospective patient record study. Quality and Safety in Health care. 2009;18:297-302.
3. Vincent C, Neale G, Woloshynowych M. Adverse events in British hospitals: preliminary retrospective record review. BMJ 2001;322:517-9.

4. Zegers M. Adverse events among hospitalized patients: results and methodological aspects of a record review study. Amsterdam: Free University, 2009.

5. Thomas AN, Galvin I. Patient safety incidents associated with equipment in critical care: a review of reports to the UK national patient safety agency. Anaesthesia 2008;63:1193-7.

6. Bhasale AL, Graeme C, Miller C, et al. Analysing potential harm in Australian general practice: an incident-monitoring study. Med J Aust 1998:169:73-6.

7. Cullen D, Bates D, Small S, et al. The incident reporting system does not detect adverse events: a problem for quality improvement. Jt Comm J Qual Improv 1995:21:541-8.

8. Cooper JB, Newbower RS, Kitz RJ. An analysis of major errors and equipment failures in anesthesia management: considerations for prevention and detection. Anesthesiology 1984;60:34-42.

9. Cooper JB, Newbower RS, Long CD, et al. Preventable anesthesia mishaps: a study of human factors. Qual Saf Health Care 2002;11:277-82.

10. Reason J. Human error: models and management. BMJ 2000;320:768-70.

11. Dutch Healthcare Inspectorate (IGZ). Kwaliteitsborging van medische apparatuur in ziekenhuizen: verbeteringen noodzakelijk. 2002.http://www.igz.nl/15451/96651/ rapport medische_apparatuur1.pdf (Accessed 15 Apr 2009). (Dutch)

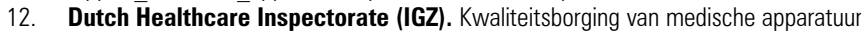
in ziekenhuizen: nog steeds onderschat. 2005 http://www.igz.n/15451/17873/ Rapport_2005-12_Kwaliteitsb1.pdf (Accessed 15 Apr 2009). (Dutch).

13. Anon. Nederlandse Vereniging van Ziekenhuizen (NVZ) Praktijkgids Risicomanagement en Medische technologie (Practice guide on Riskmanagement and Medical Technology 2007 http://www.nvz-ziekenhuizen.nl/dsresource? objectid $=43994$ gtype $=$ org (Dutch)

14. Hamilton DM, Breslawski S. Operating room scheduling: factors to consider. AORN J 1994;59:665-80.

15. Overdyk FJ, Harvey SC, Fishman RL, et al. Successful strategies for improving operating room efficiency at academic institutions. Anesth Analg 1998;86:896-906.

16. Grudich G. The critical path system: the road towards an efficient OR. AORN J 1991:53:705-14.

17. Moss JRN, Xiao Y. Improving operating room coordination: comunication pattern assessment. JONA 2000:34:93-100.

18. Healy AN, Sevdalis N, Vincent CA. Measuring intra-operative interference from distractions and interruption observed in the operating theatre. Ergonomics 2006;49:589-604.

19. Grundgeiger T, Sanderson P. Interruptions in healthcare: theoratical views. Int J Med Inform 2000;78:293-307.

20. Hickam D, Severance S, Feldstein A, et al. The effect of health working conditions on patient safety. Rockville. MD: Agency for Healthcare Research and Quality, 2003 03-E031.

21. Vuuren van W, Shea CS. Schaaf van der TW van der. The development of an incident analysis tool for the medical field. Eindhoven: Technical University, 1997.

22. Schaaf van der TW, Habraken MMP. PRISMA-Medical: a brief description. Eindhoven: Technical University, 2005.

23. Zegers M, Bruijne de MC, Wagner C, et al. Design of a retrospective patient record study on the occurrence of adverse events among patients in Dutch hospitals. BMC Health Serv Res 2007,7:27 doi: 10.1186/1472-6963-7-27.

24. Thomas EJ, Studdert DM, Brennan TA. The reliability of medical record review for estimating adverse event rates. Ann Intern Med 2002:136: 812-6.

25. Wolff A, Bourke J. Reducing medical error: a practical guide. Med J Aust 2000;173:247-51.

26. Haynes $\mathbf{A B}$, Weiser TG, Berry WR, et al. A surgical safety checklist to reduce morbidity and mortality in a global population. N Engl J Med 2009;360:491-9. 
APPENDIX 1

REGISTRATION FORM

\begin{tabular}{|l|}
\hline \multicolumn{2}{|c|}{ Registrationform equipment related incidents } \\
\hline Fill for every surgery procedure: \\
Hate: \\
Has there been an equipment related incident? \\
Exes, continue filling the reverse side of the form \\
$\square$ No, stop filling the form
\end{tabular}

Space for extra information like instructions and the length of the study 
This side to be completed in the event of an equipment related incident

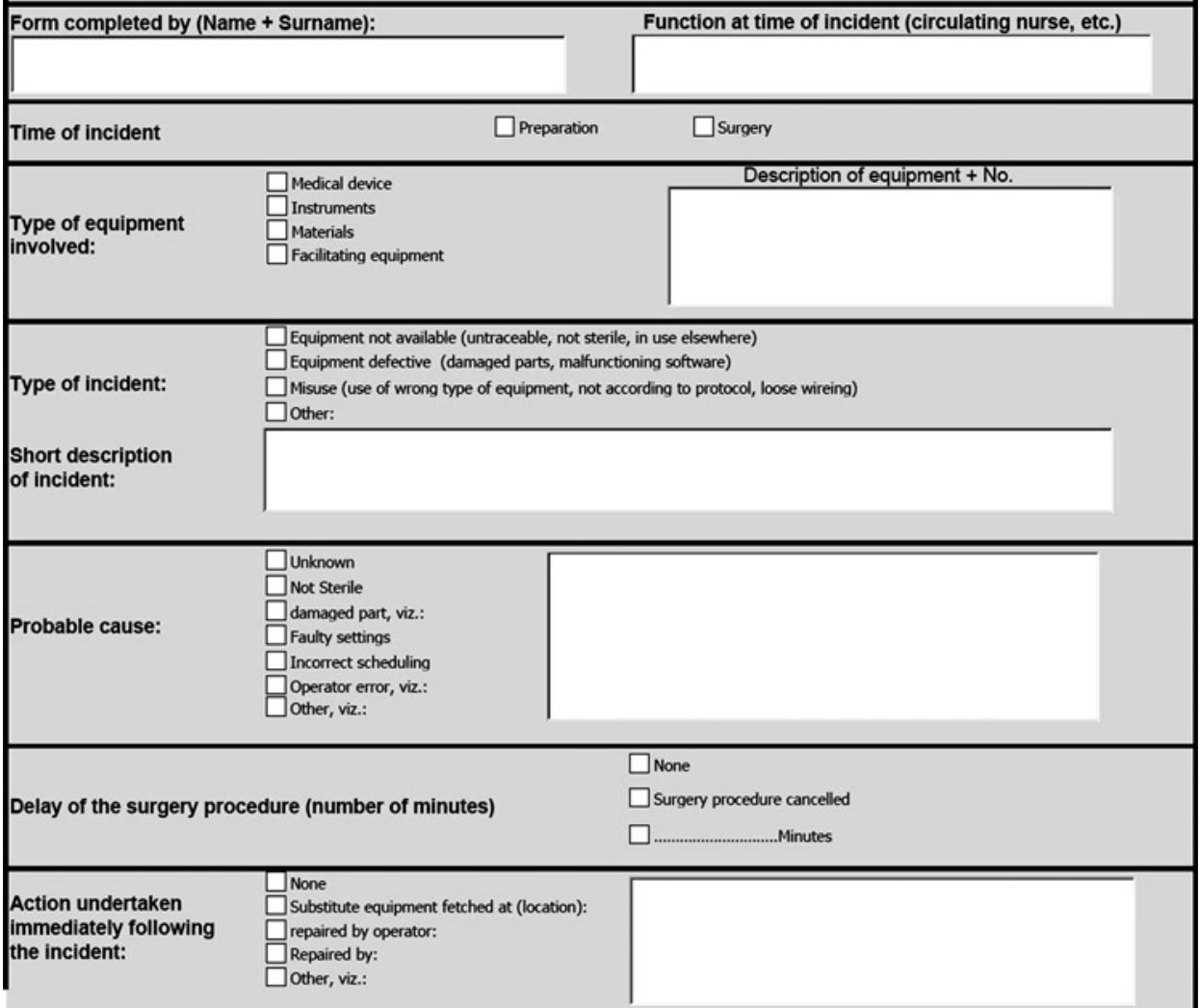

Number of persons involved in solving the problem: $1 / 2 / 3 / 4 / 5$

Number of minutes per person: $\quad$ person $1: \ldots \ldots . \min . \quad$ person $2: \ldots . . . \min . \quad$ person $3: \ldots .$. min $\quad$ person $4: \ldots .$. Min

Number of minutes the OR team had to wait until the problem was solved : ..........min

\begin{tabular}{ll|}
\hline & $\square$ None \\
consequences to patient: & $\square$ Longer Anaesthesia \\
& $\square$ surgery procedure cancelled \\
& $\square$ Physical trauma
\end{tabular}

Other departments informed?

$\square$ No $\square$ yes, ...................

Had the incident any effect on the OR schedule

$\square$ Not to my knowledge

$\square$ Yes, viz.: 